\title{
Highly enantioselective arylation of aromatic aldehydes, promoted by chiral phosphinite ligands
}

\author{
Liliana A. Soares (PG), Helena D. de Salles (IC), Paulo H. Schneider ${ }^{\star}$ (PQ).
}

Instituto de Química, Universidade Federal do Rio Grande do Sul - Av. Bento Gonçalves, 9500, 91501-970,

Porto Alegre, RS, Brasil

*Corresponding author.Tel.: 51 33086293, e-mail: paulos@iq.ufrgs.br

Keywords: diarylmethanols, boronic acids, phosphinites.

\section{INTRODUCTION}

Enantiopure compounds production is becoming increasingly important, and for this purpose the asymmetric synthesis, particularly asymmetric catalysis, have been highlighted as an efficient method. In this context the nucleophilic addition to carbonyl compounds have received much attention, specially the asymmetric arylation of aldehydes and ketones.

In this work we present the synthesis of new phosphinite ligands with an oxazolidinic ring in its structure. In order to modulate the structure of the ligands aiming the optimization of the asymmetric induction, based on a six member ring N,P transition state, some variations of substituents in strategic positions of the basic structure of the ligand were made.

\section{RESULTS AND DISCUSSION}

The asymmetric amino-phosphinite ligands can be prepared from $L$-Serine, in satisfactory global yields (10 - 32\%) (Scheme 1).
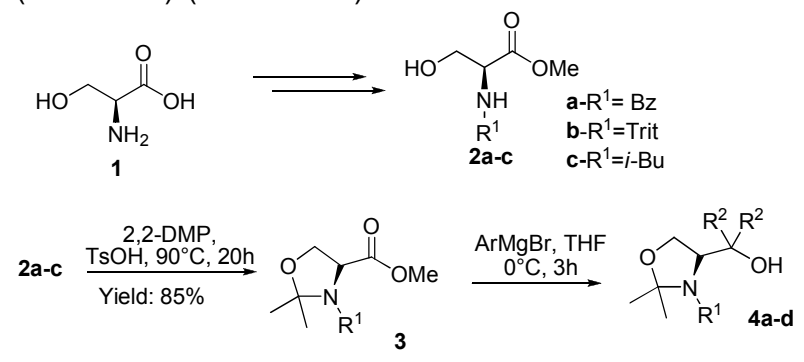

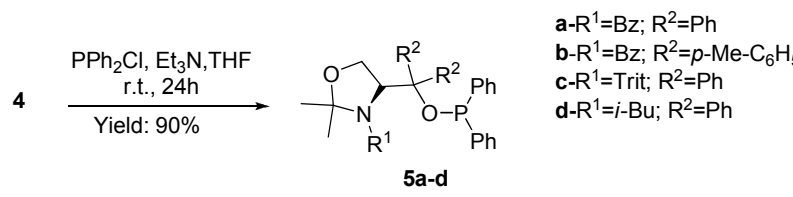

Scheme 1: Synthesis of phosphinites from $L$-serine.

This strategy permits a flexibility in the synthetic route. The versatility in introducing different groups at positions $R^{1}$ and $R^{2}$ as well as on carbon 2 of the oxazolidine ring allows the modulation of steric and eletronic features of the ligand.

$14^{\text {th }}$ Brazilian Meeting on Organic Synthesis - 14 $4^{\text {th }}$ BMOS - September 01-05, 2011-Brasilia, Brazil
Some results of the catalytic activity of the phospinites are shown in table 1 . The reaction furnished the product in good yields and when ligand 5d was used excellent enantiomeric excesses were obtained.

Table 1: Enantiosselective arylation of p-tolualdehyde

\begin{tabular}{|c|c|c|c|c|c|}
\hline & $\hat{N}^{\mathrm{B}(\mathrm{OH})_{2}}$ & $\begin{array}{c}\mathrm{L}^{*}, \mathrm{Et}_{2} \mathrm{Z} \\
\text { toluene }\end{array}$ & $\varepsilon$ & & \\
\hline Entry & Ligand & Temperature & $\mathrm{mol} \% \mathbf{5 a}$ & Yield* & e.e. \\
\hline 1 & $5 a$ & r.t. & 10 & $98 \%$ & $39 \%$ \\
\hline 2 & $5 a$ & $0^{\circ} \mathrm{C}$ & 10 & $75 \%$ & $67 \%$ \\
\hline 3 & $5 a$ & $0^{\circ} \mathrm{C}$ & 20 & $83 \%$ & $66 \%$ \\
\hline 4 & $5 a$ & $-15^{\circ} \mathrm{C}$ & 20 & $65 \%$ & $53 \%$ \\
\hline 5 & $5 c$ & $0^{\circ} \mathrm{C}$ & $10 \%$ & $46 \%$ & $52 \%$ \\
\hline 6 & $5 d$ & $\mathrm{O}^{\circ} \mathrm{C}$ & $0 \%$ & $50 \%$ & $92 \%$ \\
\hline
\end{tabular}

\section{CONCLUSION}

These preliminary results showed that phosphinite ligands have a good activity as catalysts as well as inducers of asymmetry in the propoused reaction. Further studies are in progress in order to analyze the efficiency of these ligands against different substrates.

\section{ACKNOWLEDGEMENTS}

CNPq, UFRGS, CAPES, INCT-Cat and FAPERGS.

\section{REFERENCES}

${ }^{1}$ Paixão, M. W. , Braga, A. L., Lüdtke, D. S. J. Braz. Chem. Soc., 2008, 5, 813.

${ }^{2}$ Bolm, C.; Gladysz, J., Eds. Chem. Rev. 2003, 103, 2761

${ }^{3}$ Rudolph, J.; Bolm, C.; Norrby, P. O. J. Am. Chem. Soc. 2005, $127,1548$.

${ }^{4}$ Fontes, M. Verdaguer, x. Solá , L. Pericás, M. A. Riera, A. J.

Org.Chem. 2004, 69, 253 